\title{
Exosomal MicroRNA MiR-1246 Promotes Cell Proliferation, Invasion and Drug Resistance by Targeting CCNG2 in Breast Cancer
}

\author{
Xiu Juan Li $i^{a, b}$ Zhao Jun Ren ${ }^{c}$ Jin Hai Tanga, ${ }^{a, b, d}$ Qiao Yu ${ }^{b}$ \\ aThe First Clinical School of Nanjing Medical University, Nanjing; 'Department of General Surgery, \\ Jiangsu Cancer Hospital, Jiangsu Institute of Cancer Research, Nanjing Medical University Affiliated \\ Cancer Hospital, Nanjing; 'Department of Pathology, Jiangsu Cancer Hospital, Jiangsu Institute of \\ Cancer Research, Nanjing Medical University Affiliated Cancer Hospital, Nanjing; dDepartment of \\ General Surgery, the First Affiliated Hospital with Nanjing Medical University, Nanjing, China
}

\section{Key Words}

Breast cancer • Exosomes • miR-1246 • CCNG2

\begin{abstract}
Background/Aims: Treatment of breast cancer remains a clinical challenge. This study aims to validate exosomal microRNA-1246 (miR-1246) as a serum biomarker for breast cancer and understand the underlying mechanism in breast cancer progression. Methods: The expression levels of endogenous and exosomal miRNAs were examined by real time PCR, and the expression level of the target protein was detected by western blot. Scanning electron and confocal microscopy were used to characterize exosomes and to study their uptake and transfer. Luciferase reporter plasmids and its mutant were used to confirm direct targeting. Furthermore, the functional significance of exosomal miR-1246 was estimated by invasion assay and cell viability assay. Results: In this study, we demonstrate that exosomes carrying microRNA can be transferred among different cell lines through direct uptake. miR-1246 is highly expressed in metastatic breast cancer MDA-MB-231 cells compared to non-metastatic breast cancer cells or non-malignant breast cells. Moreover, miR-1246 can suppress the expression level of its target gene, Cyclin-G2 (CCNG2), indicating its functional significance. Finally, treatment with exosomes derived from MDA-MB-231 cells could enhance the viability, migration and chemotherapy resistance of non-malignant HMLE cells. Conclusions: Together, our results support an important role of exosomes and exosomal miRNAs in regulating breast tumor progression, which highlights their potential for applications in miRNA-based therapeutics.




\section{Cellular Physiology Cell Physiol Biochem 2017;44:1741-1748 \begin{tabular}{l|l} 
and Biochemistry POI: 10.1159/000485780 & $\begin{array}{l}\text { (c) } 2017 \text { The Author(s). Published by S. Karger AG, Basel } \\
\text { www.karger.com/cpb }\end{array}$
\end{tabular}}

Li et al.: Exosomal miR-1246 Promotes Breast Cancer Progression by Targeting CCNG2

\section{Introduction}

Breast cancer is one of the most common malignant tumors among females. The fiveyear survival rate decreases from $90 \%$ for early-stage breast cancer to $20 \%$ for metastatic breast cancer. Metastasis is the major challenge in the treatment of breast cancer. The molecular pathogenesis behind the development of such metastatic advances is an area of intense research, and recent study of the role of extracellular vesicles, called exosomes, has shown promise in explaining metastasis. Recent studies have confirmed the idea that these exosomes can carry and deliver microRNAs to recipient cells [1]. Cancer-secreted exosomal microRNAs are emerging as mediators of cancer progression and metastasis [1-3]. Additionally, exosomal microRNAs may endow recipient cells with resistance to chemotherapy. Among all miRNAs investigated, miR-1246 has drawn much attention and has been found to function as a proto-oncogene in lung and other cancers $[4,5]$. Recently, it was reported that miR-1246 was strongly up-regulated in breast cancer [6]. Despite the important role of miR-1246 in breast cancer, the detailed mechanism remains unclear.

There are 8 species of cyclins reported in mammals, cyclins A through $\mathrm{H}$, which share a conserved amino acid sequence of approximately 90 residues, called the cyclin box. The amino acid sequence of cyclin G is well conserved among mammals. Cyclin G2 (CCNG2) is tightly regulated through the cell cycle. CCNG2 functions as a tumor-suppressor gene [7] and was down-regulated in thyroid [8), oral [9], and breast cancers [10].

Although, CCNG2 has been demonstrated to be associated with the development of breast cancer [11], there remain numerous unanswered questions regarding the etiology of this disease. However, the mechanism regulating CCNG2 expression in breast cancer is still not understood. Herein, using breast cancer cells and clinical samples from breast cancer patients, we found that miR-1246 is up-regulated in patients with breast cancer, especially in those with metastatic breast cancer cell lines. We also confirmed that CCNG2 is downregulated in breast cancer. miR-1246 derived from MDA-MB-231 cells can be transferred to non-malignant HMLE cells via exosomes. Moreover, the transferred miR-1246 can promote invasion in HMLE cells in part by targeting a known miR-1246 target, CCNG2.

\section{Materials and Methods}

\section{Cell culture}

The human cells, MCF-7 and MDA-MB-231, were purchased from American Type Culture Collection (ATCC, Manassas, VA, USA) and cultured in RPMI-1640 with 10\% FBS (Sigma, St. Louis, MO). MCF-10A and HMLE cells were cultured in DMEM/F12K supplemented with growth factor hEGF, hydrocortisone, insulin and 100 units of penicillin/ml and $100 \mathrm{mg}$ of streptomycin/ml. Cells were incubated at $37 \mathrm{C}$ and supplemented with 5\% CO2 in a humidified chamber. Cells used for exosome isolation were cultured in medium with exosome-depleted serum. Exosome-depleted serum was prepared by ultracentrifugation at $120,000 \times \mathrm{g}$ for 16 hours at $4 \mathrm{C}$, followed by passage through a $0.22-\mu \mathrm{m}$ filter (Millipore) prior to use.

\section{Exosome isolation and labeling}

Exosomes were isolated from medium collected after $48 \mathrm{~h}$ by differential centrifugations. Briefly, the collected culture mixture was centrifuged at $300 \times \mathrm{g}$ for $10 \mathrm{~min}$, followed by $2000 \times \mathrm{g}$ for $25 \mathrm{~min}$ [12]. The supernatant was further filtered by a $0.22-\mu \mathrm{M}$ filter (Millipore). The obtained medium was centrifuged at 100 , $000 \times \mathrm{g}$ for $60 \mathrm{~min}$ at $4 \mathrm{C}$ to pellet exosomes. The supernatant was discarded, and then, the pellet was washed with PBS, ultracentrifuged and finally resuspended again in PBS. Purified exosomes were fluorescently labeled using PKH26, a red membrane dye (Sigma), according to the protocol. Cytofluorimetric analysis (BD FACSCalibur, USA) was performed to detect surface molecules using a fluorescein isothiocyanate(FITC)conjugated antibody directed against Tsg101 and calnexin (DakoCytomation, Denmark).

\section{MiRNA microarray}

Total RNA was extracted using the MirVana miRNA Isolation Kit (Ambion, AM1560). The RNA was labeled using the FlashTag RNA Labeling Kit (Genishere), according to the manufacturer's recommendations. 


\section{Cellular Physiology Cell Physiol Biochem 2017;44:1741-1748 \\ \begin{tabular}{ll|l} 
and Biochemistry Published onlıne: December 06, 2017 & $\begin{array}{l}\text { C } 2017 \text { The Author(s). Published by S. Karger AG, Basel } \\
\text { www.karger.com/cpb }\end{array}$ \\
\hline
\end{tabular}}

Li et al.: Exosomal miR-1246 Promotes Breast Cancer Progression by Targeting CCNG2

Hybridization and washing were performed using the Affymetrix Fluidics Station 450 and Hybridization Oven 640 under standard conditions. The Affymetrix GeneChip miRNA 2.0 Array contains 15, 644 probe sets, including 1105 human mature miRNAs. The raw data were treated using the miRNA QC tool software (Affymetrix).

\section{Quantitative RT-PCR ( $q R T-P C R$ )}

Total RNA from cells was extracted using TRIzol reagent (Invitrogen), and total RNA from exosomes was extracted using a Total Exosome RNA and Protein Isolation kit (Thermo Fisher Scientific) according to the protocol recommended by the manufacturer. Quantitative RT-PCR (qRT-PCR) was performed using an ABI7500 instrument (Applied Biosystems) using primers purchased from Applied Biosystems. The miRNA concentration was normalized to the endogenous control RNU6B. The following primers were used for the Taqman assay: human miR-1246 (custom order) and RNU6B(001093).

\section{Cell growth, migration and invasion assay}

For the viability assay, cells were seeded in 96-well plates, and $10 \mu \mathrm{l}$ of Cell Count Kit-8 (CCK-8; Sigma) solution was added into each well. Then, cells were incubated for 4 hours, and the absorption value at $450 \mathrm{~nm}$ was measured. Transwell migration and invasion assays were conducted in 24-well chambers precoated without (migration) or with (invasion) Matrigel (BD BioCoat). In brief, exosomes from MDA-MB-231miR-1246 cells were added to the upper chamber and were incubated for 24 hours to allow cell migration through the membrane. Finally, migrated cells were fixed and counted.

\section{Western blotting}

Exosomes were directly used for protein analysis. The protein concentration of cells and exosomes was determined using a protein assay kit (Bio-Rad), and samples were separated on SDS polyacrylamide gels for western blotting analysis. An anti-CCNG2 antibody was purchased from Abcam (Cambridge, UK), and anti$\beta$-actin antibody was purchased from Sigma-Aldrich.

\section{Vector constructs and lentiviral production}

The lentiviral pLenti-III-miR-1246 vector and its empty pLenti-III vector (Applied Biological) were cotransfected with pCAG-HIVgp and pCMV-VSV-G-RSV-Rev into MDA-MB-231 cells (Gene Copoeia). Cells were infected with lentivirus and selected using $1 \mu \mathrm{g} \mathrm{ml}^{-1}$ puromycin for 4 weeks, to establish stable miR-1246 and control transfectants. The CCNG2 coding sequences lacking miR1246 target sites in their 3'UTR were transfected into the stable miR-1246 transfectants using FuGENE 6 Reagent (Promega).

Statistical analysis

Differences between subgroups were analyzed using Student's t-test and were considered significant at a threshold of $\mathrm{P}<0.01$.

\section{Results}

Characterization of exosomes released from cancer cells

To determine whether microRNAcarrying exosomes can be released from breast cancer cells, we incubated four cell lines, i.e., MCF-10A, HMLE, MCF-7 and MDA-MB-231, in exosome-free medium. The exosomes in the conditioned media were isolated by serial centrifugations and filtration. The harvested exosomes were then resuspended in PBS and examined by scanning electron microscopy (SEM). Shown in Fig. 1 https://www.ncbi.nlm.nih.

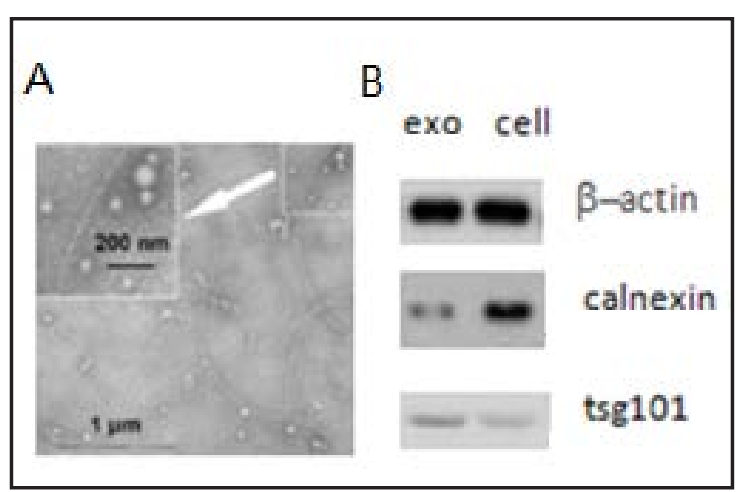

Fig. 1. Characterization of exosomes. A, Electron micrograph of exosomes isolated from MDA-MB-231 conditioned medium, revealing the typical morphology and size (20-100 nm).B, Western blot showing presence of tsg101 protein in exosome fraction, but not in whole cell lysate; presence of calnexin protein in cell lysate, but not in exosome fraction. 


\begin{abstract}
gov/pmc/articles/ P M C 4258287 / figure / F ig 1 / A are the exosomes isolated from MDAMB-231 cells; their size was within the characteristic diameter range of 20-100 nm. Next, a cell-specific marker, calnexin, was used to provide a quantification of the cell lysates; $\beta$-actin and Tsg101 were present both in cell lysate and exosomes (Fig. 1B). These results confirmed that the vesicles isolated from the conditional media were the exosomes.
\end{abstract}

\section{Quantitative RT- \\ PCR profiling \\ for exosomal microRNAs \\ $\mathrm{H}$ a v i n g d e monstrated that exosomes are released}

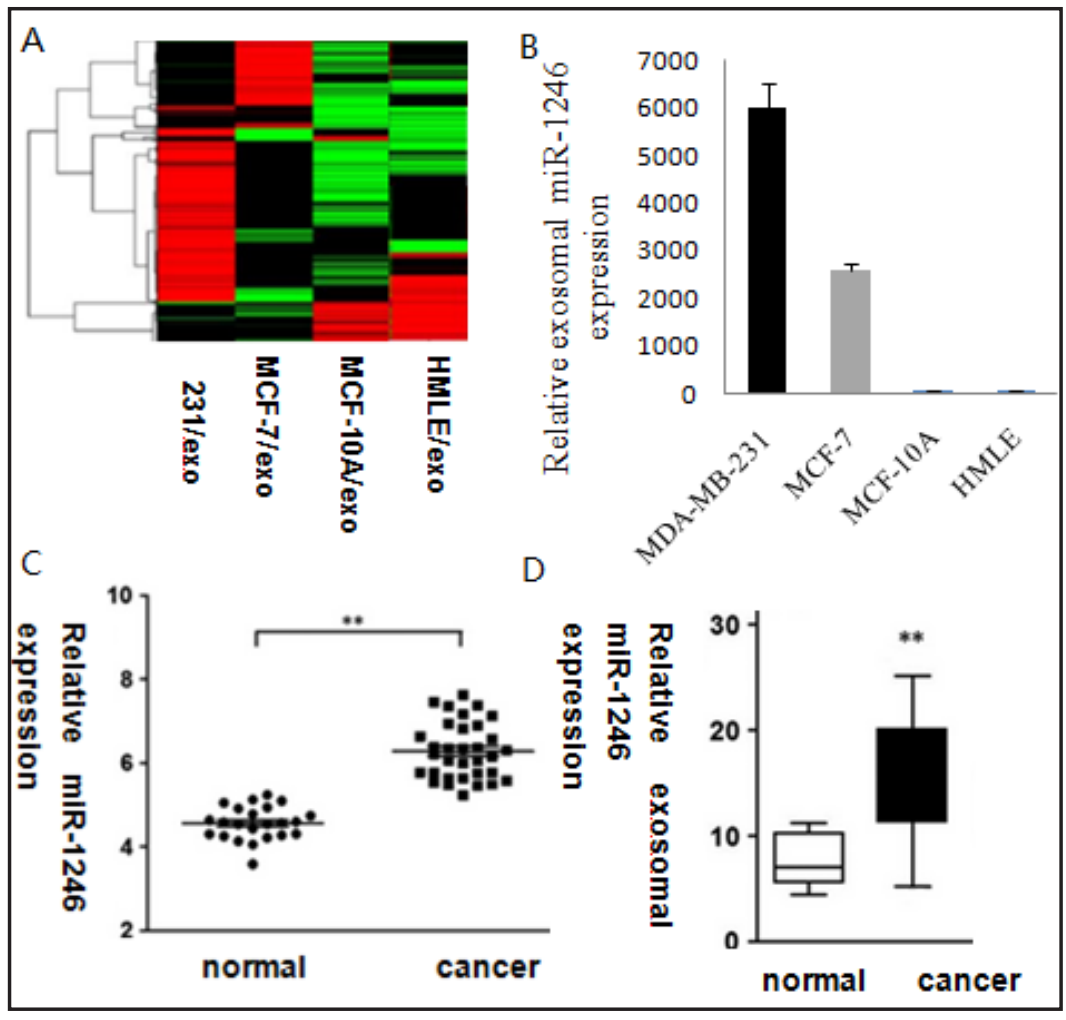

Fig. 2. Up-regulation of miR-1246 in MDA-MB-231 cells. Hierarchical cluster analysis of exosomal miRNA expression profiles in MDA-MB-231, MCF-7, and MCF-10A compared with HMLE cells (A); expression of exosomal miR1246 was validated by qRT-PCR (B). Detection of differential expression of intracellular (C) and extracellular (D) miR-1246 in tumor tissue of breast cancer patients and normal donors as determined by qRT-PCR. ${ }^{* *} \mathrm{P}<0.01$.

from breast cancer cells and then taken up by various types of cells, we determined what microRNAs are secreted via exosomes. We chose MCF-10A, HMLE, MCF-7 and MDA-MB-231 cells for comparison. We profiled the microRNAs secreted in the media in these 4 cell lines (Fig. 2A). Importantly, exosomal miR-1246 was highly expressed in MDA-MB-231 cells, whereas its expression was extremely low in HMLE and MCF-10A cells. Next, we determined the extracellular levels of miR-1246 in different breast cancer cells ranging from epithelial to metastatic by real time PCR (Fig. 2B). Since miR-1246 has significantly high expression at the extracellular level in MDA-MB-231 cells compared to HMLE cells and has been shown to play a vital role in breast cancer invasion and metastasis [13], we focused on miR-1246 in the following experiments. Furthermore, we analyzed the expression levels of miR-1246 in breast cancer and normal breast tissues by qRT-PCR. We observed a highly significant expression of miR-1246 in tumor samples( $n=56)$, relative to normal tissues ( $n=19)$ (Fig. 2C). Considering the role of exosomes as a vehicle for miR-1246, we also isolated cell-free serum from breast cancer patients $(n=56)$ and normal patients $(n=19)$. Our results confirmed that the expression of miR-1246 was also up-regulated in the serum from breast cancer patients (Fig. 2D).

\section{Transfer of miR-1246 through exosomes}

To determine whether miR-1246 could be taken up by various types of cells, we isolated exosomes from MDA-MB-231 cells and incubated them with HMLE cells. The uptake of miR-1246 by HMLE cells was then determined by qRT-PCR. We found a 5 -fold increase of intracellular miR-1246 in HMLE cells incubated with exosomes derived from MDA-MB-231 


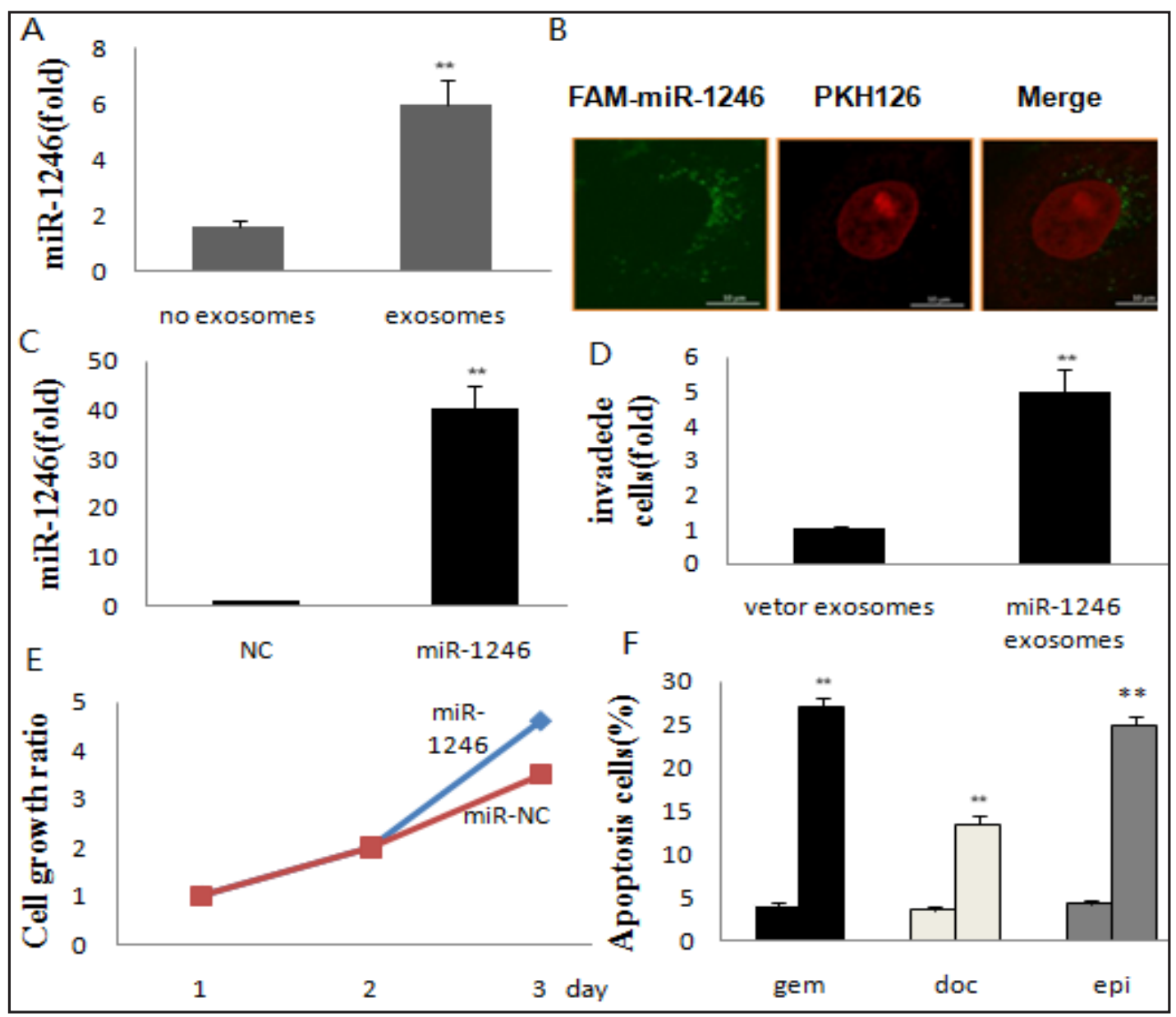

Fig. 3. Uptake of miR-1246 by HMLE cells and exosomal miR-1246 promotes cell invasion, cell growth, and chemotherapy resistance. A, Exosomal miR-1246 was isolated from MDA-MB-231 cells and then added to HMLE cell culture. The control received the exosome-free medium. U6 RNA levels were used as an internal control. B, Detection of FAM-miR-1246 in the exosome-treated HMLE cells. HMLE cells were co-cultured with MDA-MB-231 cells that had been transfected with FAM-labeled-miR-1246 using a transwell, without direct contact. C, We cloned miR-1246 in a lentiviral vector and generated cells stably expressing miR-1246 in MDA-MB-231, and the secretory level of miR-1246 by real time PCR was performed. D, Cell invasion was assessed by transwell invasion assay with HMLE cells treated with either PBS or MDA-MB-231-exosomes. Cell growth was determined using an in vitro CCK-8 assay at the indicated times (E). Cells were treated with gem, doc, and epi, and cell apoptosis was analyzed by flow cytometry after $48 \mathrm{hrs}(\mathrm{F})$. ${ }^{* *} \mathrm{P}<0.01$.

cells compared to controls (Fig. 3A). In addition, to confirm that transfer of miR-1246 from donor cells to the recipient cells was through exosomes, we isolated the exosomes from the culture medium of MDA-MB-231 cells transfected with FAM-labeled miR-1246. The isolated exosomes were then added to HMLE cells. Next, the miR-1246 signal was detected by confocal microscopy $24 \mathrm{~h}$ later (Fig. 3B). These results suggested that extracellular miR1246 from MDA-MB-231 cells can be transferred to HMLE cells through exosomes among various types of cells.

Up-regulation of endogenous miR-1246 promotes exosome-enhanced cell proliferation, migration and chemotherapy resistance

To test the functions of miR-1246 inrecipient cells, MDA-MB-231 cells were transfected with miR-1246, or the control (miR-NC) and cultured with the exosomes isolated from the media of HMLE cells. We next checked the expression of miR-1246 by real time PCR, which 


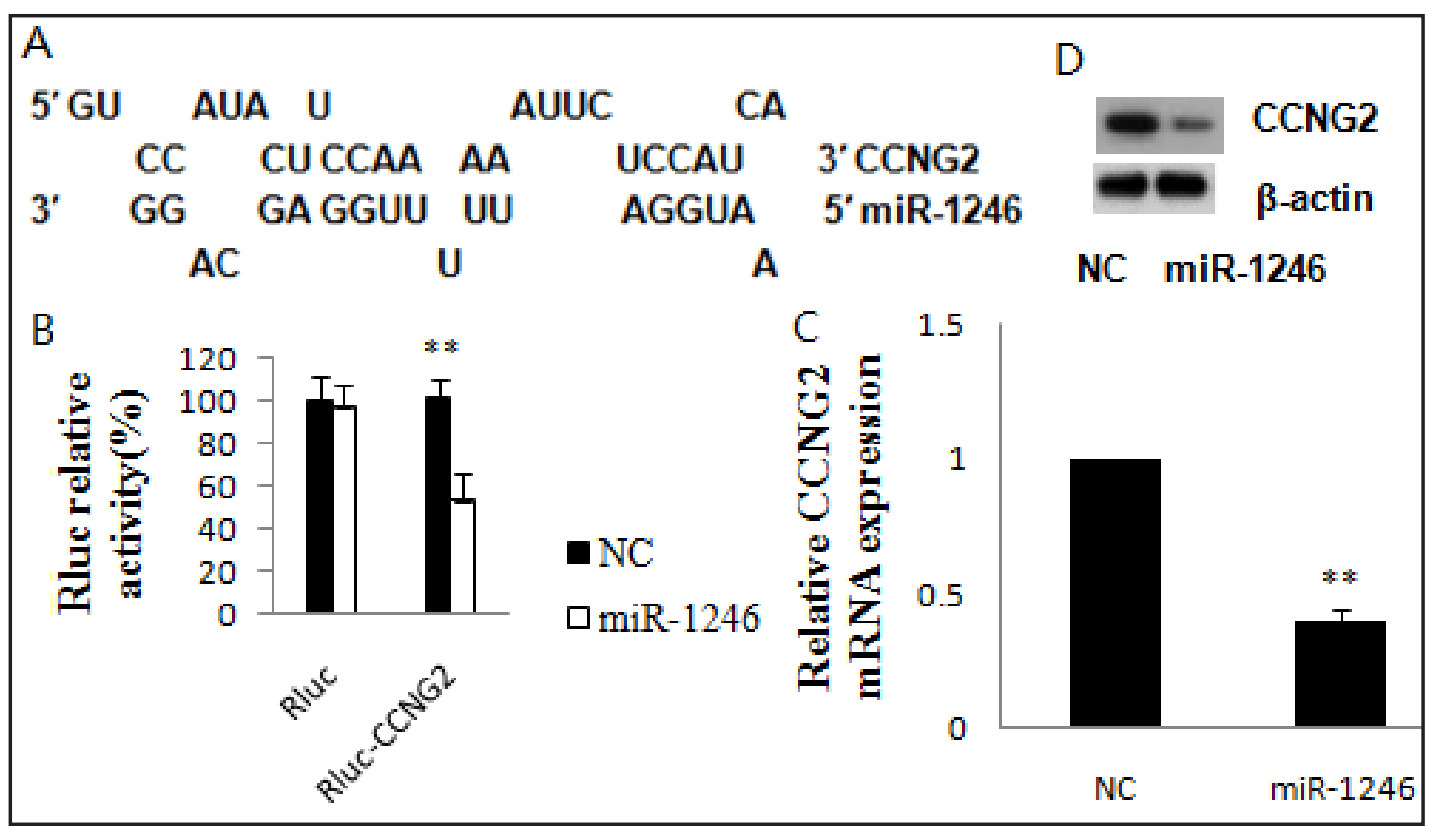

Fig. 4. miR-1246 directly targets and inhibits CCNG2 expression. (A), Putative seed-matching sites between miR-1246 and 3'-UTR of CCNG2. (B), Luciferase reporter assay was performed to detect the relative luciferase activities of WT and mut CCNG2 reporters. Renilla luciferase vector was used as an internal control. (C,D), Suppression of CCNG2 in HMLE cells by exosomal miR-1246. Data represent mean \pm s.d. of three experiments; ${ }^{* *} \mathrm{P}<0.01$.

confirmed the overexpression of exosomal miR-1246 by over 40 -fold compared to the control vector (Fig. 3C). After $24 \mathrm{~h}$ incubation of HMLE cells with the enriched exosomes derived from miR-1246 and control vector, there was significant increased invasion ability compared to the control vector (Fig. 3D). Similarly. adding exosomes from MDA-MB-231 cells transfected with miR-1246 enhanced cell growth compared with the control vector (Fig. 3E). To evaluate the effect of miR-1246-containing exosomes on drug resistance, HMLE cells were treated with docetaxel (doc), epirubicin (epi) or gemcitabine (gem), and then, their cell proliferation and cell apoptosis rates were analyzed. The CCK8 assay demonstrated that HMLE cells incubated with exosomes from MDA-MB-231 cells transfected with miR-1246 resulted in resistance to doc, epi and gem. Cell apoptosis was analyzed by flow cytometry, and the result showed that apoptosis rates of HMLE cells were significantly decreased after treatment with exosomes from MDA-MB-231 cells transfected with miR-1246 (Fig. 3F).Taken together, these data confirmed that miR-1246-containing exosomes show a tumor-promoting role in breast cancer, and up-regulation of miR-1246 can promote cell proliferation, migration and drug resistance.

\section{MiR-1246 directly targets CCNG2}

To understand the tumor-promoting role of miR-1246 in breast cancer, we selected one target gene of miR-1246 based on previously described roles as a tumor suppressor through the TargetScan program (www.targetscan.org), and we found that seed-matching sites exist between miR-1246 and the 3'-UTR of CCNG2 (Fig. 4A). These seed-matching sites are absent in the mutant CCNG2 gene (CCNG2-MUT). Furthermore, dual-luciferase reporter assay was performed to determine whether CCNG2 is a direct target of miR-1246. As shown in Fig. 4B, miR-1246 transfection decreased the luciferase activity of wild-type CCNG2, but not that of mutant CCNG2, suggesting that miR-1246 can inhibit the expression of CCNG2 by direct binding to the $3^{\prime}$ UTR. In addition, western blotting analysis and real time PCR analysis also demonstrated that exosomes from MDA-MB-231 transfected with miR-1246 both reduced CCNG2 mRNA and protein expression. (Fig. 4C and D). 


\section{Cellular Physiology Cell Physiol Biochem 2017;44:1741-1748 \begin{tabular}{l|l|l} 
and Biochemistry Published onlIne: December 06, 2017 & $\begin{array}{l}\text { (c) } 2017 \text { The Author(s). Published by S. Karger AG, Basel } \\
\text { www.karger.com/cpb }\end{array}$ \\
\hline
\end{tabular}

\section{Discussion}

In the present study, we identified functional oncogenic miRNAs that can be delivered from the metastatic breast cancer cell line MDA-MB-231 to the normal breast cell line through exosomes. Notably, exosomal miR-1246 induced a tumor-promoting phenotype, including increased cell proliferation, migration and drug resistance. In addition, miR1246 directly targets CCNG2 expression by binding to its 3'UTR. Many studies have evaluated the importance of exosomes in cancer progression [14, 15]; for instance, exosomes secreted by highly metastatic cells contribute significantly to cancer progression of poorly metastatic cells, which is consistent with the idea that cancer cells interact with each other through exosomes. We found that exosomes isolated from MDA-MB-231 cells could induce malignant features in HMLE cells by increasing their cell growth and cell invasion. One recent study reported that exosomal miR-10b from metastatic MDA-MB-231 cells was capable of inducing invasion ability upon uptake in normal breast epithelial HMLE cells [16]. Thus, the exosomes play a role in the establishment of the metastatic niche by communication between cancer cells and normal cells [17]. Increasing evidence indicates that extracellular miRNAs can have a significant role in tumor progression $[18,19]$. In the present study, the oncomiR miR-1246 was significantly enriched in exosomes and was responsible for the promotion of the metastatic potential of MDA-MB-231 cells. Thus, migration and invasion abilities of MDA-MB-231 cells were increased upon overexpression of miR-1246. Similarly, extracellular miR-1246 promoted breast cancer proliferation and enhanced chemoresistance. Further development of exosomal miR-1246 in serum as a predictor of chemotherapy resistance could improve treatment planning. New advances in gene therapy, such as potential delivery vehicles for miRNAs, could facilitate development of anti-miR-1246 therapeutic strategies. On the other hand, we found that CCNG2 is a direct target of miR-1246. Our results show for the first time that CCNG2 is also regulated by miRNAs and can be directly targeted and downregulated by miR-1246. In this regard, CCNG2 could be another therapeutic target that directly regulates the tumor-promoting function of miR-1246. Overall, our study demonstrates a crucial role for cancer cell-derived exosomes and exosomal miRNAs in cancer progression. Oncogenic microRNAs such as miR-1246, secreted by breast cancer cells, can influence the adjacent and distant normal cells, which can lead to outcomes in favor of tumor progression. Based on these results, we envision that targeting exosomal microRNAs may provide an alternative approach for breast cancer intervention.

Triple-negative breast cancer is characterized by the behavior of high invasive growth. Therefore, we chose MDA-MB-231 cells as our research focus. We aimed to elucidate the potential mechanism of tumor progression. However, "estimating the impact of estrogen receptor on the connection between miR-1246 and CCNG2" will be our future research direction.

\section{Acknowledgements}

This work was supported by the National Natural Science Foundation of China (81702612).

\section{Disclosure Statement}

The authors declare no conflicts of interest.

\section{References}

1 Valadi H, Ekstr€om K, Bossios A, Sjöstrand M, Lee JJ, Lötvall JO: Exosome-mediated transfer of mRNAs and microRNAs is a novel mechanism of genetic exchange between cells. Nat Cell Biol 2007;9:654-659. 


\section{Cellular Physiology Cell Physiol Biochem 2017:44:1741-1748 \begin{tabular}{ll|l}
\hline DOI: 10.1159/000485780 & $\begin{array}{l}\text { () } 2017 \text { The Author(s). Published by S. Karger AG, Basel } \\
\text { www.karger.com/cpb }\end{array}$ \\
\hline
\end{tabular}}

Li et al.: Exosomal miR-1246 Promotes Breast Cancer Progression by Targeting CCNG2

- Hoshino A, Costa-Silva B, Shen TL, Rodrigues G, Hashimoto A, Tesic Mark M, Molina H, Kohsaka S, Di Giannatale A, Ceder S, Singh S, Williams C, Soplop N, Uryu K, Pharmer L, King T, Bojmar L, Davies AE, Ararso Y, Zhang T, Zhang H, Hernandez J, Weiss JM, Dumont-Cole VD, Kramer K, Wexler LH, Narendran A, Schwartz GK, Healey JH, Sandstrom P, Labori KJ, Kure EH, Grandgenett PM, Hollingsworth MA, de Sousa M, Kaur S, Jain M, Mallya K, Batra SK, Jarnagin WR, Brady MS, Fodstad O, Muller V, Pantel K, Minn AJ, Bissell MJ, Garcia BA, Kang Y, Rajasekhar VK, Ghajar CM, Matei I, Peinado H, Bromberg J, Lyden D: Tumour exosome integrins determine organotropic metastasis. Nature 2015;527:329-335.

- Melo SA, Sugimoto H, O’Connell JT, Kato N, Villanueva A, Vidal A, Qiu L, Vitkin E, Perelman LT, Melo CA, Lucci A, Ivan C, Calin GA, Kalluri R: Cancer exosomes perform cell-independent microRNA biogenesis and promote tumorigenesis. Cancer Cell 2014;26:707-721.

-4 Zhang WC, Chin TM, Yang H, Nga ME, Lunny DP, Lim EK, Sun LL, Pang YH, Leow YN, Malusay SR, Lim PX, Lee JZ, Tan BJ, Shyh-Chang N, Lim EH, Lim WT, Tan DS, Tan EH, Tai BC, Soo RA, Tam WL, Lim B: Tumourinitiating cell-specific miR-1246 and miR-1290 expression converge to promote non-small cell lung cancer progression. Nat Commun 2016;7:11702.

5 Sakha S, Muramatsu T, Ueda K, Inazawa J: Exosomal microRNA miR-1246 induces cell motility and invasion through the regulation of DENND2D in oral squamous cell carcinoma. Sci Rep 2016;6:38750.

6 Zhong S, Chen X, Wang D, Zhang X, Shen H, Yang S, Lv M, Tang J, Zhao J: MicroRNA expression profiles of drug-resistance breast cancer cells and their exosomes. Oncotarget 2016;7:19601-19609.

7 Bates S, Rowan S, Vousden KH: Characterisation of human cyclin G1 and G2: DNA damage inducible genes. Oncogene 1996;13:1103-1109.

-8 Ito Y, Yoshida H, Uruno T, Nakano K, Takamura Y, Miya A, Kobayashi K, Yokozawa T, Matsuzuka F, Kuma K, Miyauchi A: Decreased expression of cyclin G2 is significantly linked to the malignant transformation of papillary carcinoma of the thyroid. Anticancer Res 2003;23:2335-2338.

-9 Kim Y, Shintani S, Kohno Y, Zhang R, Wong DT: Cyclin G2 dysregulation in human oral cancer. Cancer Res 2004;64:8980-8986.

10 Montagner M, Enzo E, Forcato M, Zanconato F, Parenti A, Rampazzo E, Basso G, Leo G, Rosato A, Bicciato S, Cordenonsi M, Piccolo S: SHARP1 suppresses breast cancer metastasis by promoting degradation of hypoxia-inducible factors. Nature 2012;487:380-384.

11 Chang YY, Kuo WH, Hung JH, Lee CY, Lee YH, Chang YC, Lin WC, Shen CY, Huang CS, Hsieh FJ, Lai LC, Tsai $\mathrm{MH}$, Chang KJ, Chuang EY: Deregulated microRNAs in triple-negative breast cancer revealed by deep sequencing. Mol Cancer 2015;14:36.

12 Raposo G, Nijman HW, Stoorvogel W, Liejendekker R, Harding CV, Melief CJ, Geuze HJ: B lymphocytes secrete antigen-presenting vesicles. J Exp Med 1996;183:1161-1172.

13 Hannafon BN, Trigoso YD, Calloway CL, Zhao YD, Lum DH, Welm AL, Zhao ZJ, Blick KE, Dooley WC, Ding WQ: Plasma exosome microRNAs are indicative of breast cancer. Breast Cancer Res 2016;18:90.

$\checkmark 14$ Hasegawa S, Eguchi H, Nagano H, Konno M, Tomimaru Y, Wada H, Hama N, Kawamoto K, Kobayashi S, Nishida N, Koseki J, Nishimura T,Gotoh N, Ohno S, Yabuta N, Nojima H, Mori M, Doki Y, Ishii H: MicroRNA-1246 expression associated with CCNG2-mediated chemoresistance and stemness in pancreatic cancer. Br J Cancer 2014;111:1572-1580.

-15 Wang S, Zeng Y, Zhou JM, Nie SL, Peng Q, Gong J, Huo JR: MicroRNA-1246 promotes growth and metastasis of colorectal cancer cells involving CCNG2 reduction. Mol Med Rep 2016;13:273-280.

16 Singh R, Pochampally R, Watabe K, Lu Z, Mo YY: Exosome-mediated transfer of miR-10b promotes cell invasion in breast cancer. Mol Cancer 2014;13:256.

17 Peinado H: Melanoma exosomes educate bone marrow progenitor cells toward a pro-metastatic phenotype through MET. Nat Med 2012;18:883-891.

18 Li J, Yu J, Zhang H, Wang B, Guo H, Bai J, Wang J, Dong Y, Zhao Y, Wang Y: Exosomes-Derived MiR-302b Suppresses Lung Cancer Cell Proliferation and Migration via TGFßRII Inhibition. Cell Physiol Biochem 2016;38:1715-1726.

19 Zhang J, Zhang HD, Yao YF, Zhong SL, Zhao JH, Tang JH: $\beta$-Elemene Reverses Chemoresistance of Breast Cancer Cells by Reducing Resistance Transmission via Exosomes. Cell Physiol Biochem 2015;36:22742286. 